\title{
CODE PREFERENCE IN LINGUISTIC LANDSCAPE: A FORENSIC APPROACH TO THE TOP-DOWN SIGNBOARDS
}

\author{
Ayesha Jamil \\ PhD Scholar, National University of Modern Language, Islamabad \\ ayeshajamil121@gmail.com \\ Ghazala Kausar \\ Assistant Professor, National University of Modern Language, Islamabad \\ gkausar@numl.edu.pk
}

\begin{abstract}
The present study is an endeavor to examine the linguistic landscape of Islamabad and Lahore in the light of the existing language policy as vividly written in the Constitution of Pakistan 1973. The language policy and code preference are clearly visible through the signboards deployed at various public places to inform, guide, warn and direct the viewer. A sample of three hundred top-down signboards was photographically collected through purposive sampling technique. The theoretical frameworks of Spolsky and Cooper (1991) and geosemiotics by Scollon and Scollon (2003) have been employed to uncover the underlying competition that exists between Urdu and English for dominance. Quantitative and qualitative data analysis show that Urdu is the preferred code but often found embellished with English vocabulary. The names of the public offices are in English which highlights the inefficiency of the government authorities to implement Urdu as an official language in true letter and spirit.
\end{abstract}

Keywords: Linguistic landscape, top- down signboards, language policy, code preference

\section{INTRODUCTION}

Language is omnipresent in the form of advertisements, logos of various brands, names of shops, price tags of commodities and traffic signs that constitute the linguistic landscape of an area. This linguistic landscape projects specific values that act as a mediator between interpretation of inhabitants about themselves and their relation to others in space thus creating a socially constructed space imbued with meaning. This socially constructed space mirrors the language choices of a community, patterns of language, contact phenomenon, numerous facets of literacy and regulations especially in any multilingual setting. The analysis of signs scattered in the environment also serves as an entry point into the field of language policy where languages are seen to be struggling for their existence or grass roots resistance to political agendas.

Certainly, it is quite difficult to find a monolingual linguistic landscape due to dissemination and circulation of English in countries where English is not used and the usage of novel names, brand slogans and shop logos in monolingual countries using only English as a medium of communication (Gorter, 2006) so linguistic landscape plays a vital role in symbolizing the legitimacy and priority of specific languages over other languages in a given territory. According to Dal Negro (2008), there is a strong relationship that exists between language policy and linguistic landscape of any space. Hence, a linguistic landscape of any space reflects language policy of a country while ascertaining how certain languages can be used in a society. It becomes more evident through the top-down signboards which are allocated by government authorities in the light of rules and regulations of language policy for the public to educate and guide them. As Shohamy and Gorter (2008) note, in their research that the display of certain linguistic items of certain languages in a certain way gives out indirect and direct messages that on a broad level refers to marginality and centrality of specific languages in a society respectively.

Pakistan is a country having six significant and fifty eight minor ones and comes under the category of multilingualism (Rahman, 2008). Urdu being the national language is extensively spoken and understood in the urban areas of Pakistan. It serves as a link between people coming from multiethnic groups of Pakistan thus proves to be a symbol of national integration. Besides being the 
national language, the constitution of Pakistan 1973 gives Urdu the position of official language and asserts that arrangements should be made to replace English, but English relishes the repute of official language and is deeply rooted in every walk of life. It is a symbol of power and status. However, a competition exists between the two languages to gain a high position and attain a symbol of prestige that is quite visible through the linguistic landscape.

\section{Research Questions}

The research questions are as follows:

1) Which languages are visible on the top-down signboards of Islamabad and Lahore?

2) Which language occupies a prominent place on the top-down signboards of Islamabad and Lahore?

3) To what extent do the top-down signboards exhibit the language policy of Pakistan?

\section{REVIEW OF LITERATURE}

\section{Linguistic landscape and Top-down signboards}

The notion of the term Linguistic Landscape has been defined and elaborated by various linguists. According to Shohamy and Gorter (2008), the language present in the environment occupies the meaning of the term while this idea is elaborated further by Stroud and Mpendukana (2009) as other way of representation of any space with the help of language used in communication, sign boards and performances by speakers. A more clear and precise definition of Linguistic Landscape is put forward by Landry and Bourhis (1997) as

"The language of public road signs, advertising billboards, street names, place names, commercial shop signs, and public signs on government buildings combine to form the linguistic landscape of a given territory, region or urban agglomeration."

Apparently, this explanation of the term clearly pinpoints the visibility and display of a language on the signboards but implicitly this representation of language sheds light on political and social scenarios, cultural and identity globalization, prevalent language policies and above all laws of a country. Due to globalization and scientific advancement, the world has faced tremendous changes in every all fields of life but issues relating to language conflict and language planning has risen to prominence. For the first time in 1970s, the notion of linguistic landscape was launched to counter and address the issues regarding language policing and language planning. Further the concept captured the attention of sociolinguists in 1990.At this stage a new dimension was added to the previously existing literature with an aim to view LL as arbitrary or coincidental happening as opposed to a deliberate construction.

This coincidental happening and occurrence of languages in a territory performs two major roles namely an informational role and a symbolic role as stated by Landry and Bourhis (1997).The informational function of texts in public spaces serves as a means to offer information, guide visitors, provide orientation, represent the rules and regulations, specify the limits of a territory and attract customers while the symbolic role played by a sign mirrors the repute of a language which is enjoyed within a plurilingual scenario.

Moreover, linguists (Ben-Rafael, Shohamy, Hasan, Amara, \& Trumper-Hecht, 2006) have categorized the signs keeping in view the linguistic landscape actors that participate actively in construction of signs based on preferential tendencies and deliberate choices. These actors can be individuals, public or private institutions, corporate firms or even global associations encompassing diverse stratification of a society. In short, there are two broad categorization of actors who are play their roles in linguistic landscape construction. These categories are named as private and public. The first category of private actors by employing personal autonomy plan bottom-up signboards as per own choices and employ individual tactics. The private actors produce private signboards like signs identifying shops, advertisements of various brands and logos. On the other hand, the public actors design top-down signs that belong to regulatory discourse with an endeavor to regulate the movement and behavior of inhabitants through the use and display of traffic signals and related devices like public notices. So, these devices aim to instruct the people in the light of the rules and regulations as prescribed in the law. A lot of interest has been shown by the researchers Rosenbaum and Nadel (1977) , Tulp (1978), Calvet (2006), Schlick (2003) and Singh, Itagi, and Singh (2002) to examine the processes related to language choice, language mixing and language policy on bottom-up sign and top-down signs. Cenoz and Gorter (2006) attempted to compare the linguistic landscape of Basque 
and Friesland in research and concluded that three languages including state language, minority language and English are seen on the signs while the language policy is only reflected through the use of minority language.

\section{Language Policy and Historical Background}

Within Pakistan, English language has a colonial past. It was once the language used by the colonizers for communication but at present it has grasped firm roots in every walk of life especially in the colonized countries. Quite recently, Coleman (2011) and Wedell (2011) have identified three major roles being performed by English language i.e. functional, utilitarian and practical levels having positive, negative and neutral connotations respectively in the countries who are striving hard to become scientifically advanced and modernized technologically. While Kachru (1986) has reported English being playing two major functions in a multilingual scenario like Pakistan; the first is the repute of an official language while the second function is being used by the citizens for communication.

English language is one of the legacies which Pakistan has received after the partition of the subcontinent. This language was the language of British colonizers who ruled over the subcontinent more than a century. Pakistan was the part of the subcontinent before 1947 and witnessed Mughal period and was ruled by both Muslim and English. Under the reign of Muslim Emperors, the Muslim culture and traditions flourished. In the Mughal Era, Persian being the official language that was used to discuss the stately matters and business affairs of the country state affairs, business and other matters of the day. British with the slogan to civilize the Indians of the subcontinent introduced English though the inhabitants did not feel any need for a linguistic change (Mehboob, 2002). This change in language was utterly based on the language policing by the British with an endeavor to exert an influence on the behavior of Indians with respect to acquire, learn, structure and functionally allocate their languages (Cooper \& Cooper, 1989). Massive changes were brought by the British during their rule in the subcontinent. The colonizers left the subcontinent by dividing it into India and Pakistan but English is still enjoying a high status at present which is a question attempted to answer by many sociolinguists. Mehboob (2002) reports the role of the political power and to be more specific military power places a language at the highest pedestal. A sudden change in the native language will echo a concurrent change in the power structures of a society also. It was in 1835 when the switch of languages took place in the subcontinent. This linguistic switch led to the change in the power structures as well as heralded the changing attitude of the masses towards the English.

The partition led to the implementation of a three languages policy. According to this policy, Urdu was given the label of national language, English the official language while assigning a provincial language for every province of Pakistan like Balochi language to be used in Baluchistan Pashto to be used in Khyber Pakhtunha, Sindhi language used in Sindh, and Punjabi language for the province, Punjab. A change in the three-language policy was witnessed in the year 1948 into two language policy where Urdu was the national language and English the official language of Pakistan, but the latter will be superseded by Urdu once developed within ten years period. Presently, English is used for instruction purposes in educational institutions, and it is compulsory for the personnel holding high and superior public offices to be well versed in English. The Constitution of 1973 of Islamic Republic of Pakistan being first nationally approved constitution clearly announces in its Article 251, the national language and official language as Urdu and English respectively. The clauses regarding national and official language are as follows.

- Clause 1. The National Language of Pakistan is Urdu, and arrangements shall be made for its being used for official and other purposes within fifteen years from the commencing day.

- Clause 2. Subject to clause (1) the English language may be used for official purposes until arrangements are made for its replacement by Urdu.

The worthy Supreme Court of Pakistan has also notified all the government offices in the year 2015 to use Urdu in all the official documentation and at all public spaces within Pakistan but Zaidi and Zaki (2017) concluded their research and found the above mentioned clauses are null and void. This is merely a rule that is meant to distinguish between two classes: educated versus uneducated. The language of English and its proficiency by the Pakistani people is a symbol signify status quo and superiority. 
Language visibility especially in multilingual scenario often leads the law makers to design language policies since linguistic landscape is considered as means for maintenance of language promotion or reversal of language shift (Landry \& Bourhis, 1997). Manan, David, Dumanig, and Channa (2017) in their research concludes the policy governing signage and advertising in Kualalumpur as direct, elaborate, and detailed. It not only mentions the placement, font size but also the penalty for not observing the language policy when designing a sign for the city. English -Spanish language policy also exists in which English is given preference through the font size as compared to Spanish. In 1970, for the first time, Montreal, city of Quebec framed detailed regulations and policy for language visibility and still holds periodic investigations over public complaints.

\section{THEORETICAL FRAMEWORK}

The present study relies on the theoretical notion of three condition model by Spolsky and Cooper (1991) and further supplemented by geosemiotics proposed by Scollon and Scollon (2003).

According to Spolsky and Cooper (1991), there are three conditions for the producer to choose a language for any public display i.e., writer's skill in a language, the assumed reader's skill and the symbolic language. All these three conditions form a triangle of preference. The first two conditions reflect the presence of bilingualism or multilingualism where people speak different languages in a setting. Mostly sign writers are not well versed in all the languages so this hurdle can be transcended by commissioning the business of writing to sign makers only. The second condition deals with the reader's skill to understand a language with ease. The aspect of emotionality is noteworthy here since its impact attract the reader and engages them emotionally. The third condition is relevant to the present research that aims to highlight the frequency of occurrence of languages in any multilingual setting by developing a relationship between the choice of language and symbolic elucidations.

The second theoretical framework for the present endeavor has been adopted from geosemiotics. For Scollon and Scollon (2003), all signs and symbols acquire meanings from their placement in the material world. Context plays a vital role in allocating meaning and then disseminating that meaning to the viewers. Within geosemiotics, three principles are at work: principle of indexicality, principle of dialogicality and principle of selection. The study deals with the principle of selection which proposes that social actor's foreground and background some of the information by keeping in view the needs and requirements. A sign that signals a language choice reflects selection of the user which in turn serves as an identity of people living in a particular area. The allocation of codes on a single signboard is the main semiotic resource. According to Scollon and Scollon (2003), the preferred code is placed high above the peripheral one if aligned in a vertically whereas the preferred code is placed at the left position and peripheral occupies the right in horizontal axis. The circular design of a picture shows the preferred code located in the center and the less preferred code located in the periphery.

According to Dal Negro (2008), LL is a tool through which, language policing is mirrored while Puzey (2012) asserts that LL is a vital factor in reflecting the thoughts and understanding of people regarding language policy. Drawing on insights of Dal Negro (2008) and Puzey (2012), the occurrence of codes in terms of frequency and their placement on the signboards will reflect the legal policies regarding language and forensically analyze their implementation in true letter and spirit.

\section{METHODOLOGY}

The present research has employed a mix method technique. The quantitative aspect deals with the frequent visibility of each language on signboards while the qualitative aspect sheds light on the relationship between law and code preference in the light of forensic linguistics.

\section{Sample}

A sample of 300 pictures of top-down signs was collected by the researcher from ten recreational and historical places of Islamabad and Lahore including Motorway (M-2). Islamabad was chosen for being the capital of Pakistan with foreign and local inhabitants while Lahore has rich historical roots and a strong governance among all the provinces of Pakistan. Since the study is delimited to top-down signboards allocated by the government authorities so purposive sampling technique has been used. 


\section{Unit of Analysis}

In the light of Cenoz (2008) perspective, who states that unit of analysis can range from the minutest individual signage to the level of an institution so a unit of analysis for this study is a single signboard deployed at the survey areas by the government authorities. The unit of analysis is a signboard considered as a whole according to Cenoz and Gorter (2006). The data are collected through photographs since photographic documentation is considered the heart of linguistic landscape study (Scollon \& Scollon, 2003).

\section{Procedure}

After collection of data, the researcher manually allocated numbers for proper identification of each picture. Two hundred signboards were rejected based on repetition in terms of syntax and meaning so the sample of 300 pictures was reduced to 100 pictures. Moreover, the epidemic corona hindered the process of collection of samples since all public places were not accessible and closed by government authorities to avoid the spread of the disease. Each picture was coded and categorized into three categories: Urdu, English and both languages. All the data were distributed among the three categories The number of high occurrences of each category was shown quantitatively through pie chart. Qualitatively, the results were analyzed and discussed keeping in view article 251 mentioned in the Constitution of Pakistan 1973.

\section{DATA ANALYSIS}

The data have been analyzed both quantitatively and qualitatively.

\section{Quantitative Analysis}

According to geosemiotics and quantitative analysis, code preference shows language preference by the authorities and the existing language policy. Figure No. 1 showed that 50 percent signboards used Urdu language for communication purposes so we can say Urdu is the preferred code while English is used on 20 percent signboards which is quite less in number when compared to the previously mentioned first categorization. 30 percent signboards contain both the languages. These signboards are mostly translated versions to help the viewers in understanding.

\section{Figure No. 1 Code Preference}

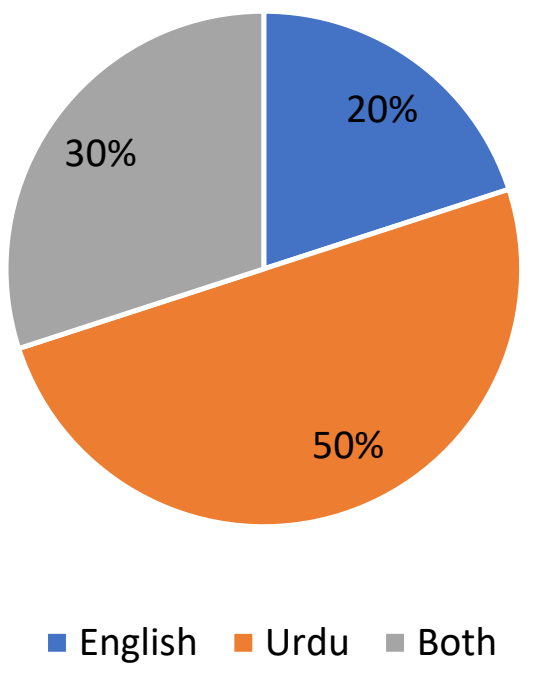

\section{Qualitative Analysis}

Using code preference and symbolic function of language adopted by (Scollon \& Scollon, 2003) and (Spolsky \& Cooper, 1991) respectively, the data have been divided into three broad categories. The first category includes signboards containing English language only. English is given preference as no Urdu translation is provided as evident from figure No.2, 3 and 4. 


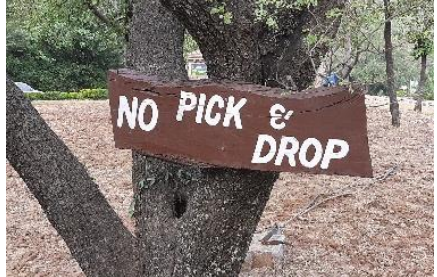

Figure 2

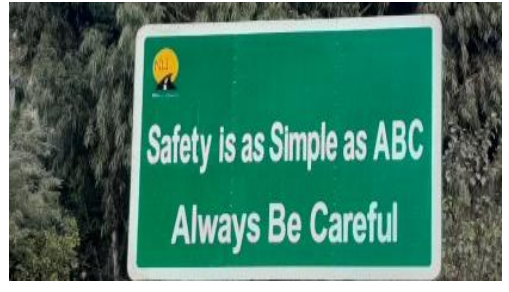

Figure 3

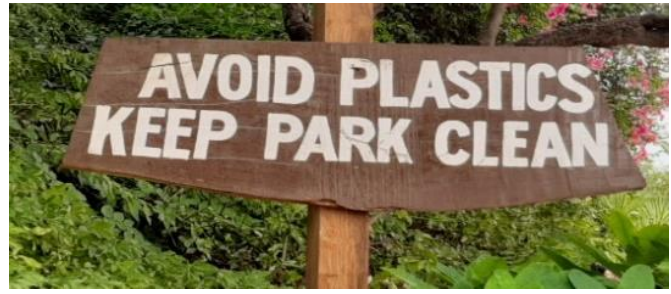

Figure 4

The second category contains Urdu only in which no English translation is provided. Here various processes at work are observed. The process of code mixing is seen in Figure No.5. Although the orthography and syntax of Urdu is followed but two nouns facemask and gloves are borrowed from English language to convey the message. Urdu vocabulary provides substitutes نقاب and دستان 2 for facemask and gloves but authorities seem to prefer usage of English words. The same phenomenon is seen in Figure No. 6 and 7. The signboard in Figure No. 7 clearly mentions four English words i.e., speed, brake, road, slippery written in Urdu while the signboard in figure 6 having both English and Urdu language translates speed into رفتار which is an Urdu word. The words road

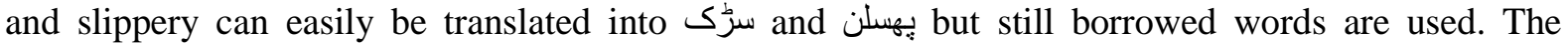
substitutes are available, and the government authorities even know the substitutes as evident from Figures No. 5, 6 and 7 where speed is translated into رفتار still it reflects the preferred use of English vocabulary by the authorities and giving less importance to Urdu language

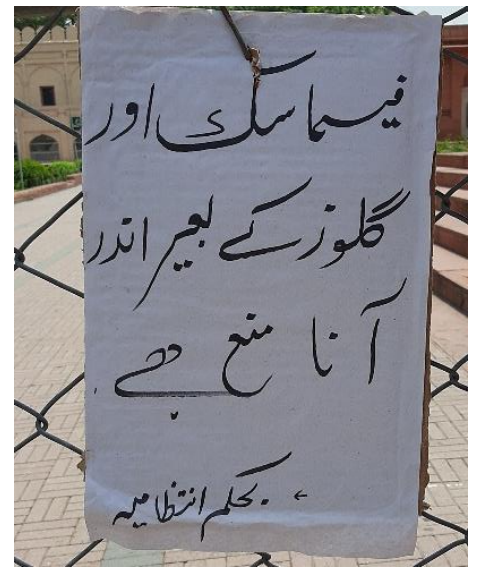

Figure 5

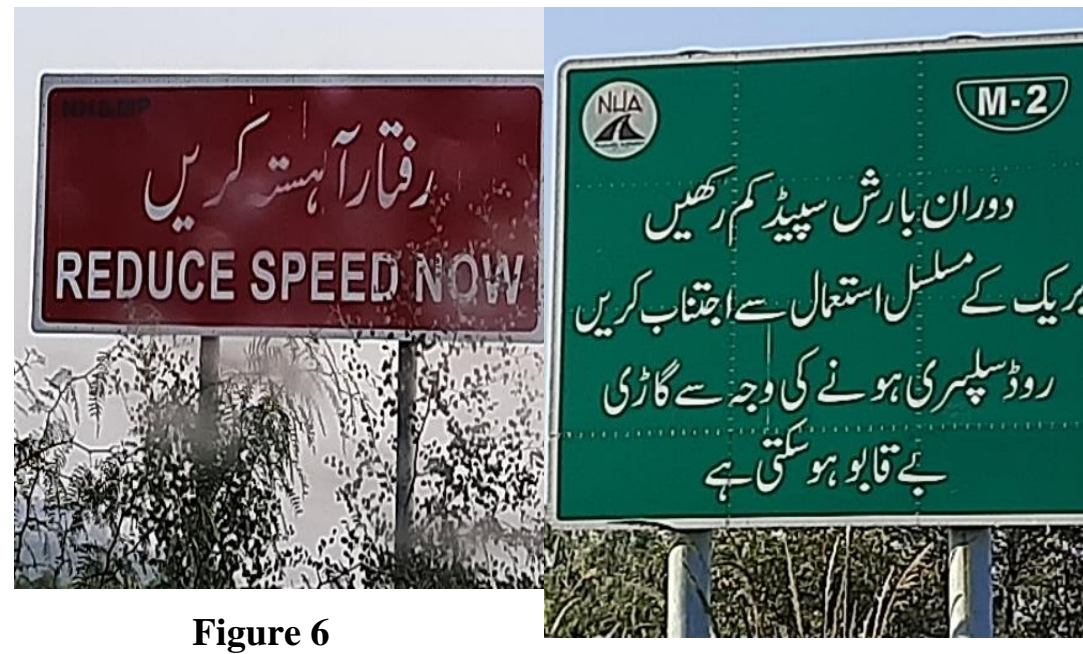

Figure 7

The signboards written in Urdu language highlight one more aspect which is again contradictory to the constitution of Pakistan. The names of the authorities such as NHA and NH \& MP in Figures 6 and 7 are written in English language irrespective of the use of language on the signboards. This phenomenon is prevalent in the second category of signboards having only Urdu as a medium of communication as shown in Figure no. 8 where PHA is written in English.

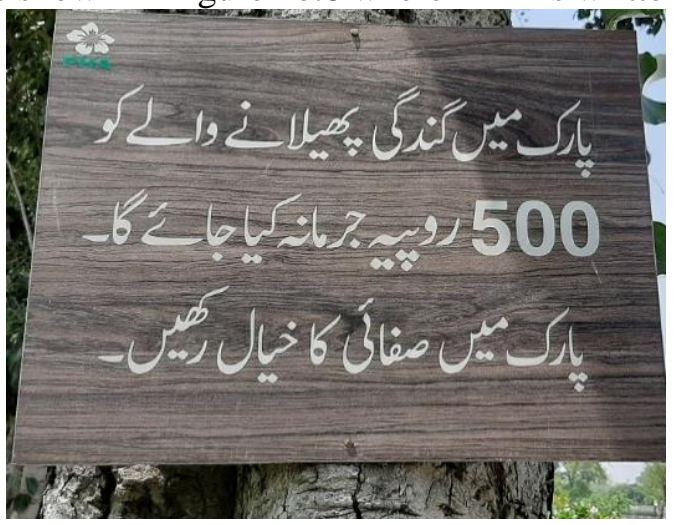

Figure 8 
The third category reflects the existence of both Urdu and English languages on a single signboard having varying patterns. Within the sample data, Urdu is the preferred code and placed high above English.

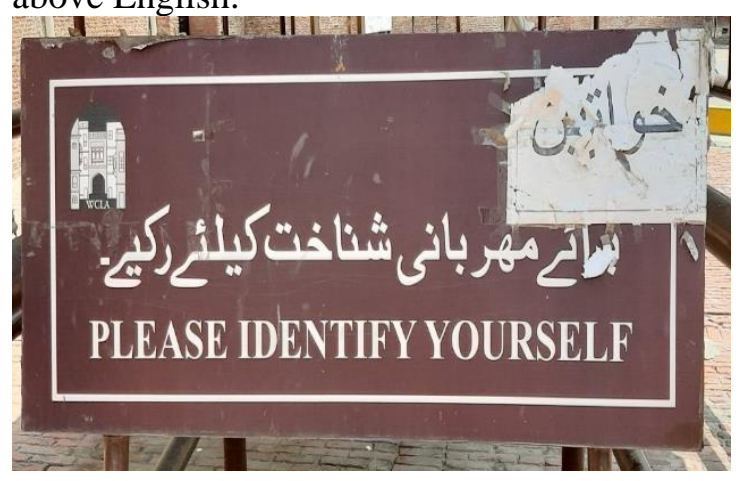

Figure 9

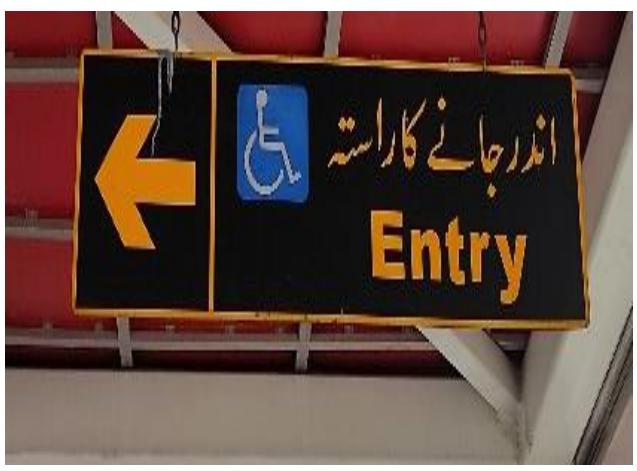

Figure 10

In the figures 9 and 10, Urdu language is given preference and is placed above English. This confirms Urdu as the preferred language as mentioned by Scollon \& Scollon (2003) under the heading of code preference. Within the data, this pattern is followed but with the exception of two pictures shown below in which English is placed above Urdu language.

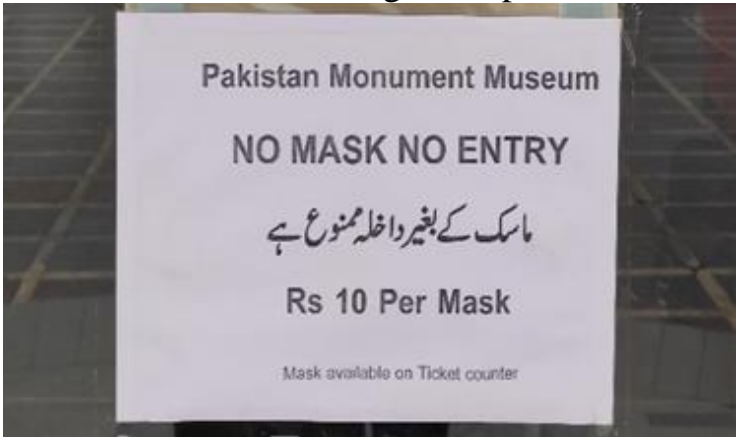

Figure 11

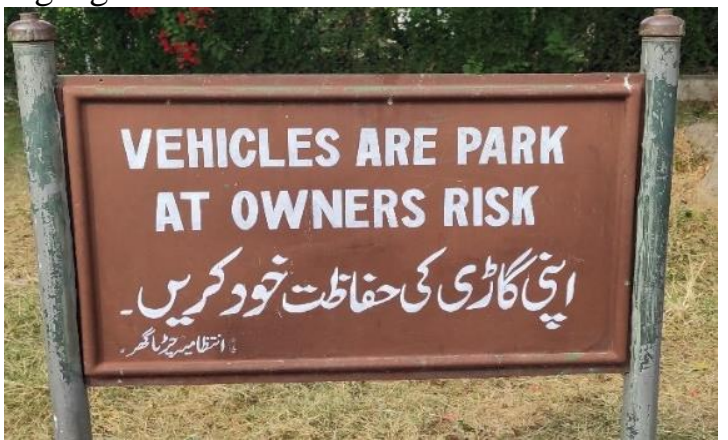

Figure 12

In figure 11, only one sentence can be seen in Urdu occupying middle position while all other text is written in English reflecting superiority of English over Urdu. While in Figure No. 12, it is quite evident that the text in English is placed at the top position while Urdu sentence is at the bottom even the sentence is grammatically incorrect in English. If viewed from the perspective of translation, the meaning conveyed has different shades. The sentence in English is in passive voice while the sentence in Urdu is an active sentence. Comparing both sentences the use of possessive pronoun along with emphatic pronoun yourself " خود "puts all the responsibility on the owner with a strong emphasis while in English no such emphasis is laid.

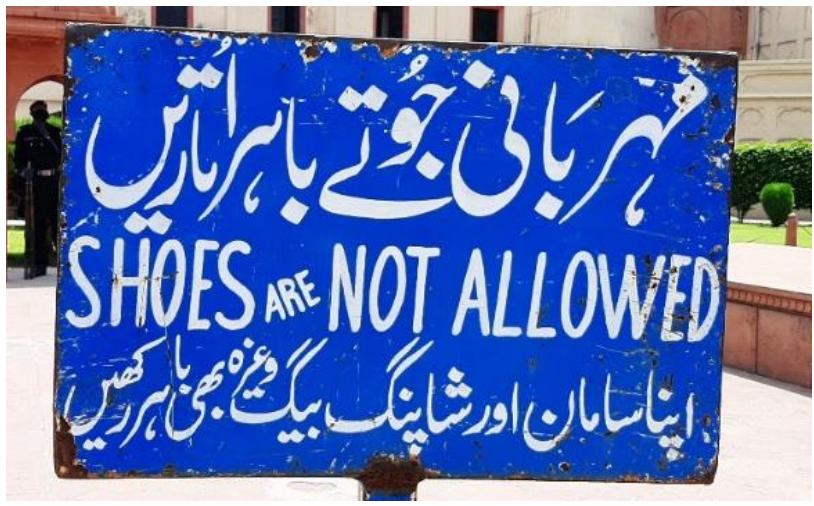

Figure 13

In figure 13, English holds middle position while Urdu is at the top and bottom. The difference in translation is quite evident. The sentence in Urdu clearly mentions to take off your shoes outside the mosque while the translated sentence just announces that shoes are not allowed. He is not 
given any option to take off his shoes before entering the mosque so the messages in both the languages lead to ambiguity owing to difference in interpretation.

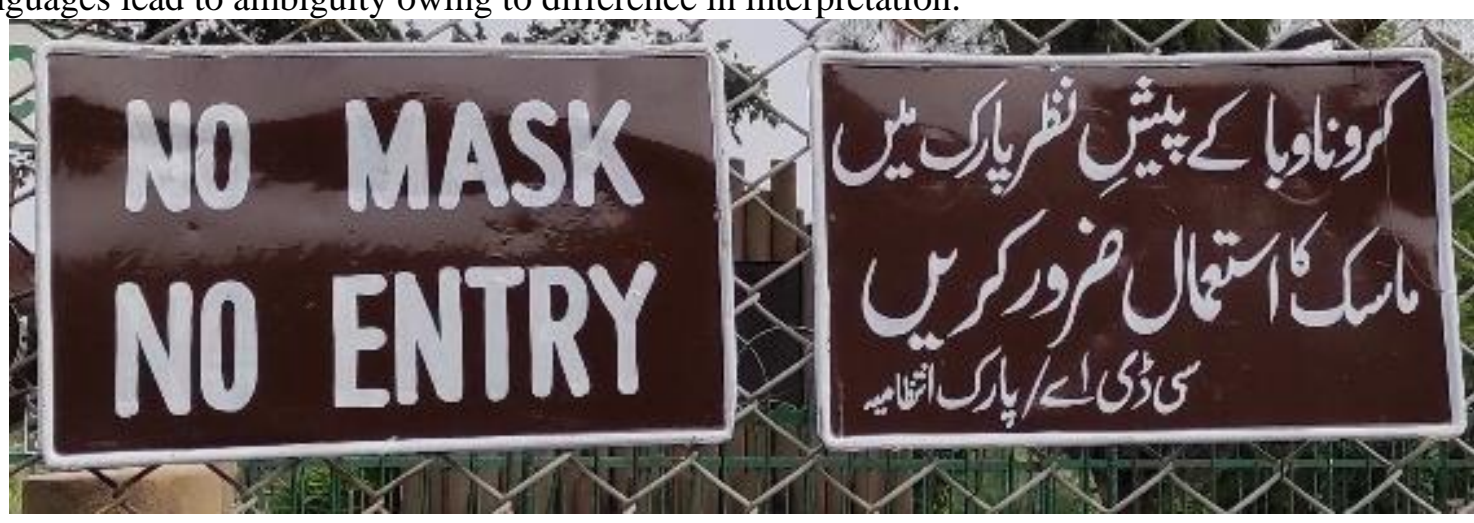

Figure 14

Within the data, it was observed that two separate signboards are allocated side by side in Urdu and English as shown in figure No.14. Although the underlying meanings are similar to some extent, but syntax is different. The signboard in English is direct, without any explanation, comprises of two phrases only, "NO MASK NO ENTRY" while the signboard in Urdu is quite elaborative and indirect in meaning. The signboard talks about the reason for wearing mask i.e., corona and indirectly directs the visitors to wear mask in the park. On the contrary, the text in English openly and in direct words instructs the visitor to wear mask otherwise entry will not be allowed. The comparison leads to semantic, pragmatic, and syntactic differences between the signboards in Urdu and English.

\section{DISCUSSION}

The citizens of Pakistan having multi-cultural and multilingual background speak Punjabi, Sindhi, Pashto, Saraiki and Balochi commonly but as a symbol of unity Urdu has been assigned to function as the official language as declared in Article 251 mentioned in constitution of 1973 of Pakistan. However, the said article also states that "English language may be used for official purposes until arrangements are made for its replacement by Urdu" But the real situation is quite ironic. English language holds a supreme position and superior to all other languages spoken in Pakistan till date and still cannot be superseded by Urdu completely. The supremacy and superiority of English is conspicuous through the display of signboards that are visible at public spaces all over Pakistan.

The analysis of the data shows the presence of Urdu and English only on the signboards for communicating rules and regulations to the masses. In view of Spolsky and Cooper (1991), all the three parameters are at play. The writers' skill, the presumed readers' skill, and the symbolic language. No doubt the motivation behind use of English is symbolic since it is an emblem of science and technology (Gorter, 2013), but in Pakistan colonization is also one of the reasons for language visibility on signboards. The proficiency in English language is a matter of status symbol in Pakistani society. In an attempt to exhibit and comprehend the current linguistic scenario of Pakistan, Zaidi and Zaki (2017) adapted De Swaan's Global language System model as shown below in figure No.15.

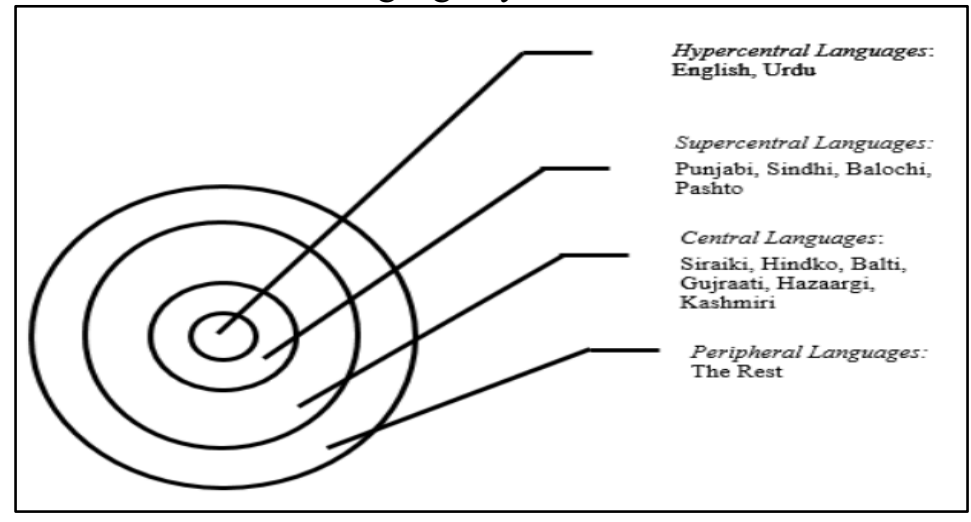

Figure 15 Global Language System 
In the light of the model by De Swaan (2013), English and Urdu are named as hyper central languages owing to their higher repute and being assigned a prestigious place as compared to super central, central and peripheral languages. The results also affirm Zaidi and Zaki (2017) adapted model because the hyper central languages are used on regulatory discourse especially top-down signboards throughout the public spaces in Islamabad and Lahore.

Viewing the collected data through the lens of geosemiotics framework, the preferred code is Urdu owing to its placement at the top position while English occupies the bottom except for two pictures. In some cases, separate signboards are installed side by side in both English and Urdu giving equal preference to both languages. A sort of competition for dominance is seen between Urdu and English languages

It is interesting to note that several words of English language have been absorbed by Urdu language. Though the Urdu vocabulary provides words for gloves, bag, facemask, road, slippery, dustbin yet the preferred vocabulary is English lexicon. The view of Kachru (1986) is hereby affirmed that the language of English can lend its users with power, social prestige, success and opportunity.

In forensic context, the constitution clearly announces Urdu as the national language but paradoxically the names of the public offices can be seen in English that confirm the supremacy of English language over Urdu and affirm the laws are mere a written piece of paper. Even the government authorities fail to implement and enforce laws within their own departments. The names along with logos like NHA, PHA, WCLA, PMA, NH\& MP, CDA follow English alphabets and vocabulary. Du Plessis (2012) also reports lack of alignment between constitutional directives and language visibility in South Africa.

The third category of signboards contains both Urdu and English languages on signboards which are found semantically, pragmatically, and syntactically apart. These differences give various shades of meaning hence leading the readers to ambiguity. Another research conducted by Manan et al. (2017) also concluded that English predominate the linguistic landscape of Pakistan due to the presence of Englishized Urdu and Urduized English while Shahzad, Hussain, Sarwat, Nabi, and Ahmed (2020) states that linguistic landscape is a means for promotion of language and cultural traditions so the visibility of English and Urdu on top down signage is rather a method to strengthen the English language in Pakistan.

\section{CONCLUSION}

Employing the geosemiotics framework, it is concluded that although the preferred code owing to the placement of language on the signboards is Urdu, yet the data have highlighted the code mixing of English into Urdu. Signboards written in Urdu are seen decorated with English vocabulary. This practice brings to light that the clause in article 251 fails to make people especially the higher authorities abide by the rules and regulations. The predominance of English is also exhibited in terms of the names of government offices. Occurrence of English lexicon within Urdu sentences on signboards is indicative of the fact that English vocabulary is means for mass communication. Although the English substitutes exist in Urdu, yet the preferred vocabulary is English within the Urdu signboards. During the analysis, it was rare to encounter such an instance in which words belonging to Urdu lexicon were used on signboards written in English. Syntactically complete sentences in Urdu are translated into phrases in English by omitting some information from the signboards. More background information is given to the audience in Urdu as compared to English. The analysis also helped to conclude that Urdu syntax along with orthography are preferable by the authorities, but English vocabulary is chosen for circulation of rules and regulations to the common masses. This situation is quite alarming and startling to behold that the government authorities, the custodian of constitution of Pakistan, are themselves working as an agent for the promotion of English through its display publicly. This one-way process of substituting Urdu words into English has been highlighted through the present research which mirrors the loss of identity by placing Urdu nearly to transcend the boundary of endangered language.

\section{REFERENCES}

Ben-Rafael, E., Shohamy, E., Hasan Amara, M., \& Trumper-Hecht, N. (2006). Linguistic landscape as symbolic construction of the public space: The case of Israel. International journal of multilingualism, 3(1), 7-30. 
Calvet, L.-J. (2006). Towards an ecology of world languages: Polity.

Cenoz, J. (2008). The acquisition of pragmatic competence and multilingualism in foreign language contexts Intercultural language use and language learning (pp. 123-140): Springer.

Cenoz, J., \& Gorter, D. (2006). Linguistic landscape and minority languages Linguistic landscape (pp. 67-80): Multilingual Matters.

Coleman, H. (2011). Dreams and realities: Developing countries and the English language: British council.

Cooper, R. L., \& Cooper, R. L. C. (1989). Language planning and social change: Cambridge University Press.

Dal Negro, S. (2008). Local policy modeling the linguistic landscape Linguistic landscape (pp. 246258): Routledge.

De Swaan, A. (2013). Words of the world: The global language system: John Wiley \& Sons.

Du Plessis, T. (2012). The role of language policy in linguistic landscape changes in a rural area of the Free State Province of South Africa. Language Matters, 43(2), 263-282.

Gorter, D. (2006). Introduction: The study of the linguistic landscape as a new approach to multilingualism. International journal of multilingualism, 3(1), 1-6.

Gorter, D. (2013). Linguistic landscapes in a multilingual world. Annual Review of Applied Linguistics, 33, 190.

Kachru, B. B. (1986). The alchemy of English: The spread, functions, and models of non-native Englishes: University of Illinois Press.

Landry, R., \& Bourhis, R. Y. (1997). Linguistic landscape and ethnolinguistic vitality: An empirical study. Journal of Language and Social Psychology, 16(1), 23-49.

Manan, S. A., David, M. K., Dumanig, F. P., \& Channa, L. A. (2017). The glocalization of English in the Pakistan linguistic landscape. World Englishes, 36(4), 645-665.

Mehboob, A. (2002). No english, no future. Language Policy in Pakistan, in Obeng, SG \& Hartford, B.(Eds.) Political Independence with Linguistic Servitude: The Politics about Languages in the Developing World (15-39). New York: Nova Science Pulishers.

Puzey, G. (2012). Two-way traffic: How linguistic landscapes reflect and influence the politics of language Minority languages in the linguistic landscape (pp. 127-147): Springer.

Rahman, T. (2008). Language policy, multilingualism and language vitality in Pakistan Lesser-known languages of South Asia (pp. 73-106): De Gruyter Mouton.

Rosenbaum, Y., \& Nadel, E. (1977). English on Keren Kayemet Street. InJ. A. Fishman, RL Cooper, \& AW Conrad (Eds.), The Spread of English (pp. 179-196): Rowley, MA: Newbury House Publishers.

Schlick, M. (2003). The English of shop signs in Europe. English today, 19(1), 3-17.

Scollon, R., \& Scollon, S. W. (2003). Discourses in place: Language in the material world: Routledge.

Shahzad, S. K., Hussain, J., Sarwat, S., Nabi, A. G., \& Ahmed, M. M. (2020). Linguistic Landscape in Promotion of Language Through Traffic Signboards: An Introduction to the Signs in Pakistani Roads and Highways. International Journal of English Linguistics, 10(6).

Shohamy, E., \& Gorter, D. (2008). Linguistic landscape: Expanding the scenery: Routledge.

Singh, U. N., Itagi, N., \& Singh, S. (2002). Linguistic landscaping: An overview: na.

Spolsky, B., \& Cooper, R. L. (1991). The languages of Jerusalem: Clarendon Press.

Stroud, C., \& Mpendukana, S. (2009). Towards a material ethnography of linguistic landscape: Multilingualism, mobility and space in a South African township 1. Journal of Sociolinguistics, 13(3), 363-386.

Tulp, S. M. (1978). Reklame en tweetaligheid: Een onderzoek naar de geografische verspreiding van franstalige en nederlandstalige affiches in Brussel. Taal en sociale integratie, 1, 261-288.

Wedell, M. (2011). More than just 'technology': English language teaching initiatives as complex educational changes. Dreams and realities: Developing countries and the English language, 269-290.

Zaidi, S. B., \& Zaki, S. (2017). English language in Pakistan: Expansion and resulting implications. Journal of Education \& Social Sciences, 5(1), 52-67. 